\title{
Evaluation of the Diagnostic Performance of Physical Examination Combined with Transvaginal Ultrasonography in Patients with Endometriosis
}

\author{
Talha TIRYAKI ${ }^{1}$, Tolga KARACAN ${ }^{1}$, Seyma YESIRALIOGLU ${ }^{1}$, Eser OZYUREK ${ }^{1}$, Huseyin KIYAK ${ }^{2}$, Engin ORAL ${ }^{3}$ \\ Istanbul, Turkey
}

\section{ABSTRACT}

OBJECTIVE: Owing to its high sensitivity and specificity, and because it is widely available, transvaginal ultrasonography is the first-line imaging test of choice used for the diagnosis of endometriosis. Ultrasonographic findings evaluated in conjunction with symptoms and signs may improve the diagnosis of endometriosis. Therefore, we hypothesized that transvaginal ultrasonography combined with physical examinations performed by physicians could predict endometriosis better in patients with symptoms suggestive of endometriosis compared with asymptomatic patients at presentation.

STUDY DESIGN: In this retrospective cohort study, the first subjective impression obtained from the history, physical examination, and transvaginal ultrasonography performed by the physician during the first visit in the outpatient clinic was taken into consideration. Patients who underwent surgery with the indication of ovarian mass were divided into two groups according to their admission types; symptomatic and asymptomatic.

RESULTS: The number of patients reported to have endometriosis histopathologically was 138;132 were in the premenopausal period (symptomatic group $n=101$, asymptomatic group $n=31$ ) and 6 were in the postmenopausal period (symptomatic group $n=1$, asymptomatic group $n=5$ ). The positive predictive value and positive likelihood ratio of the combination of pelvic examination and transvaginal ultrasonography in premenopausal symptomatic and asymptomatic patients, and postmenopausal symptomatic and asymptomatic patients were $97.8 \%, 11.5 ; 47.3 \%, 6.9 ; 25.0 \%, 4.6$; and $11.1 \%, 2.3$, respectively.

CONCLUSION: The diagnostic performance of transvaginal ultrasonography in combination with physical examination in patients with asymptomatic endometriosis cannot reach the diagnostic accuracy of physical examination combined with transvaginal ultrasonography in patients with endometriosis who present with symptoms.

Keywords: Endometriosis, Physical examination, Transvaginal sonography, Ovarian endometriosis

Gynecol Obstet Reprod Med 2020;26(2)116-122

1 Department of Obstetrics and Gynecology, University of Health Sciences, Bagcilar Research and Education Hospital, Istanbul, Turkey

2 Department of Obstetrics and Gynecology, University of Health Sciences, Kanuni Sultan Suleyman Research and Education Hospital, Istanbul, Turkey

3 Department of Obstetrics and Gynecology, Istanbul University Cerrahpasa Medical Faculty, Istanbul, Turkey

Address of Correspondence: Tolga Karacan

Merkez Mah. Mimar Sinan Cad. $\quad$ 6. Sokak, 34100, Bagcilar, Istanbul, Turkey

tolgakaracan84@gmail.com

Submitted for Publication:

20.02 .2018

12.04 .2018

ORCID IDs of the authors: TK: 0000-0002-3510-4147, EO: 0000-0002-5373-3991, EO:0000-0002-4123-6357

TT: 0000-0001-9200-3177, SY: 0000-0001-7290-2749, HK:0000-0001-7580-9179,

\begin{tabular}{|c|c|}
\hline \multirow{3}{*}{ 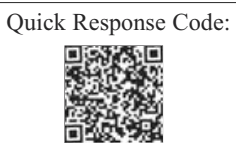 } & Access this article online \\
\hline & $\begin{array}{l}\text { Website: www.gorm.com.tr } \\
\text { e- mail: info@gorm.com.tr }\end{array}$ \\
\hline & DOI:10.201613/GORM.2018.901 \\
\hline
\end{tabular}

How to cite this article: Tiryaki T. Karacan T. Yesiralioglu S. Ozyurek E. Kiyak H. Oral E. Evaluation of the Diagnostic Performance of Physical Examination Combined with Transvaginal Ultrasonography in Patients with Endometriosis. Gynecol Obstet Reprod Med. 2020;26(2):116-122

\section{Introduction}

Endometriosis is defined as the presence of ectopic endometrial tissue outside the uterine cavity. The most common locations of endometriosis include the ovaries, peritoneum, uterine ligaments and, less commonly, the bladder, vagina and digestive tract. In general, it is estimated to occur in around $10 \%$ of women in reproductive age. This ratio increases up to $35-50 \%$ in symptomatic patients. Clinically, patients may have dysmenorrhea, deep dyspareunia, chronic pelvic pain (acyclic) and/or infertility. Although its etiology is considered to be multifactorial including environmental, immunologic, endocrinologic, and genetic factors, its specific etiology and treatment have not yet been elucidated (1-2).

The main diagnostic problems of endometriosis include detecting and determining the extent of disease, especially in the absence of an endometriotic cyst. Knowing the extent of the disease is important because it affects the planning and strategy of surgical treatment. At the same time, considering the association of endometriosis with infertility, the most accurate timing for surgery becomes important because it may 
also cause injury in the vascular structures of the ovaries or in some part of the ovarian cortex, thereby resulting in decreased ovarian reserve. Another concern emphasized in several studies is the potential risk for developing an endometrioid or clear cell carcinoma inside an endometrioma (3). Thus, establishing the correct diagnosis for endometrioma forms the basis for designing the best treatment strategy.

Owing to its high sensitivity and specificity, and because it is widely available, transvaginal ultrasonography (TVS) should be considered as the first-line imaging technique for endometrioma. As emphasized before, ultrasonographic findings evaluated in conjunction with symptoms and signs may improve the diagnosis of endometrioma (4). We hypothesized that TVS combined with the physical examination could predict endometrioma better in patients with symptoms suggestive of endometriosis (e.g. dysmenorrhea and/or chronic pelvic pain) compared with asymptomatic patients at presentation.

\section{Material and Method}

The data of 512 patients who underwent laparoscopy or laparotomy for an adnexal mass between June 2009 and November 2017 were analyzed retrospectively. The study was approved by the local institutional review board (date: 27/10/2017 and ethics committee number: 2017.10.2.05.006) and written informed consent was obtained from all participants. The patients were selected using the international classification database (ICD) codes from the medical electronic database of the hospital. Variables including age at the time of surgery, body mass index (BMI) $(\mathrm{kg} / \mathrm{m} 2)$, parity number, menopausal status, adnexal cyst size, and histologic diagnosis of the cysts were recorded.

In this retrospective cohort study, the first subjective impression obtained from the history, physical examination (e.g., digital vaginal examination) and TVS (transabdominal sonography was added on when large masses could not be fully visualized via the transvaginal route) performed by the physician during the first visit in the outpatient clinic were taken into consideration. The ultrasound brand name was Sonoscape S40® (SonoScape Co., Ltd., China). It had a real-time threedimensional 3D (4D) feature and a high-resolution LED monitor with wide viewing angle. The physician was blinded to the serum CA-125 values and magnetic resonance imaging (MRI) of the patients. All patients underwent a speculum examination; however rectal examinations were not performed on a routine basis. No bowel preparation was performed prior to sonography. Adnexal masses were detected in women who presented with gynecologic symptoms or as incidental findings. The first impression regarding the nature of the cyst was recorded routinely in the medical database at the end of the examination, and if necessary, patients were referred to the specialized units (e.g., endometriosis unit). The results of the chemical laboratory examinations (e.g., CA-125) and other imaging modalities (e.g., MRI) performed in the specialized units were not taken into consideration in our study.
Patients who underwent surgery with the indication of ovarian mass were divided into two groups according to their admission types; symptomatic (patients with symptoms that might be associated with endometriosis - noncyclic chronic pelvic pain, dysmenorrhea, dyspareunia, and subfertility -) and asymptomatic. The histologic diagnosis was the gold standard method for the adnexal mass removed surgically. The patients underwent surgery within 30 days of the initial examination, following routine anesthesia preparation. A standardized examination technique, standardized terms, and definitions were used. The sonographic presence of endometriomas was determined in accordance with the recommendations of the International Ovarian Tumor Analysis (IOTA) group (6). The presence of an endometrioma was suggested when a mass characterized by circular homogeneous, hypoechoic 'tissue' without papillary proliferations and a clear demarcation line from the ovarian parenchyma were detected using gray-scale sonography.

The exclusion criteria of the study were as follows; 1) Patients in whom endometrioma was considered as a result of the clinical examination but who were followed-up without treatment or treated medically, 2) Patients with previous endometriosis surgery or in whom hormonal therapy was initiated due to suspected endometriosis history, 3) Patients whose physician did not have an impression during initial examination, 4) Patients who underwent surgery for an adnexal cyst during pregnancy.

Although the gynecologists who contributed to the formation of data in the study had sufficient experience with TVS, they had different levels of experience with respect to the diagnosis and treatment of endometriosis specifically. The medical histories of the patients were taken verbally by the gynecologists during face-to-face appointments under the conditions of the outpatient clinic. The first subjective impressions made as a result of the physical examinations and TVS performed by the same gynecologists were recorded in the computer-based patient record system. Each scan was interpreted prospectively during the course of the real-time examination. Whenever the ultrasound examiner suggested more than one presumed diagnosis or stated that it was impossible to suggest a diagnosis, the diagnosis was classified as unidentified. The intraoperative findings of the patients were not included in the study parameters because they were beyond the scope of the study.

\section{Statistical Analysis}

The data were interpreted and verified by an independent observer. Continuous variables are expressed as mean \pm standard derivation (SD) and categorical variables are presented as frequencies and percentage. Sensitivity, specificity, positive predictive value (PPV), negative predictive value (NPV), and likelihood ratios $(\mathrm{LR} \pm$ ) were calculated with $95 \%$ confidence intervals $(\mathrm{Cl})$. The Kappa $-\mathrm{K}-$ index $( \pm 95 \% \mathrm{Cl})$ was calculated in order to evaluate the overall agreement between the preoperative diagnosis and final histology. According to Landis et al. (7), the Kappa values were interpreted as follows; $<0.20=$ 
poor, $0.21-0.40=$ fair, $0.41-0.60=$ moderate, $0.61-0.80=$ good, and $0.81-1.00=$ very good agreement. The true histology of the false-positive cases, as well as the presumed diagnoses of the false-negative cases, were indicated. For all analyses, a twotailed $\mathrm{P}$ value of $<.05$ was considered to indicate statistical significance. The Statistical Package for the Social Sciences (SPSS) version 19 was used for statistical analyses (IBM, Armonk, NY, USA).

\section{Results}

In our study, of the 512 patients who underwent surgery for various adnexal masses, $397(77.5 \%)$ were in the premenopausal period (symptomatic group $n=127$, asymptomatic group $n=270)$ and $115(22.5 \%)$ were in the postmenopausal pe- riod (symptomatic group $n=15$, asymptomatic group $n=100$ ).

The number of patients histopathologically reported as having endometrioma was 138 . Of these patients, 132/397 (33.2\%) were in the premenopausal period and 6/115 (5.2\%) were in the postmenopausal period. The mean age of patients was $32.2 \pm 8.8$ (range, 20-53) years in the premenopausal period and $55.8 \pm 5.6$ (range, $48-64$ ) years in the postmenopausal period. The characteristics of the patients in both groups are summarized in table I.

The sensitivity, specificity, PPV, NPV, accuracy, LHR +, LHR- of the combination of history, pelvic examination, and TVS used in the diagnosis of ovarian endometriosis in premenopausal and postmenopausal patients are summarized in table II-III.

Table I: The demographic datas of the patients and sonographic diameter of the masses, classified according to the based on menopausal status and symptoms

\begin{tabular}{|c|c|c|c|c|}
\hline & \multicolumn{2}{|c|}{ Premenopausal period $(n=132)$} & \multicolumn{2}{|c|}{ Postmenopausal period $(n=6)$} \\
\hline & Symptomatic group & Asymptomatic group & Symptomatic group & Asymptomatic group \\
\hline No. of patients & 101 & 31 & 1 & 5 \\
\hline Age (years)† & $32(9.1)$ [20-45] & $34.7(7.8)$ [22-53] & 54 & $56.2(6.2)$ [48-64] \\
\hline No. of parity† & $1.1(0.9)[0-3]$ & $0.9(0.6)[0-2]$ & 1 & $0.6(0.5)[0-1]$ \\
\hline Body mass index $\left(\mathrm{kg} / \mathrm{m}^{2}\right) \dagger$ & 26.8 (4.3) [19-34] & $28.2(2.5)[24-32]$ & 31.2 & $27.2(3.5)[22-34.2]$ \\
\hline Cyst size $(\mathrm{mm}) \dagger$ & $58.4(22.1)[35-180]$ & $75.2(15.5)[55-120]$ & 45 & $48(9)$ \\
\hline Indication $\ddagger$, \#, ¥ & & & & \\
\hline Suspicious for malignancy & $23(22.7)$ & $31(100)$ & $1(100)$ & $5(100)$ \\
\hline Medical treatment-resistant pain & $72(71.2)$ & - & - & - \\
\hline Medical treatment side effects & $18(17.8)$ & - & - & - \\
\hline Noncylic chronic pelvic pain $\ddagger, \S$ & $64(63.3)$ & - & $1(100)$ & - \\
\hline Dysmenorrheał,§ & $48(47.5)$ & - & - & - \\
\hline Dyspareuniał,§ & $16(15.8)$ & - & - & - \\
\hline
\end{tabular}

TThe data were expressed as mean (SD) [range]. ¥The data were expressed as $n(\%)$. §Total of percentage exceeds $100 \%$ because most patients had more than one symptoms. \#The indications were established after the imaging (e.g., MRI) and laboratory investigations (e.g., CA-125) in the endometriosis unit where patients were referred after their first visits. ¥Total of percentage exceeds $100 \%$ because the same patients had more than one indications. T: Symptoms (e.g., menstrual irregularity, hot flushes, mood changes) which are not tolerated by patients

Table II: Summary of the diagnostic results of the history and clinical examination combined with transvaginal ultrasonography

\begin{tabular}{|c|c|c|c|c|c|}
\hline & & \multicolumn{2}{|c|}{ Premenopausal period } & \multicolumn{2}{|c|}{ Postmenopausal period } \\
\hline \multirow{3}{*}{$\begin{array}{l}\text { True } \\
\text { positive }\end{array}$} & & $\begin{array}{l}\text { Preoperative } \\
\text { Diagnosis }\end{array}$ & $\begin{array}{l}\text { Histological } \\
\text { Diagnosis }\end{array}$ & $\begin{array}{l}\text { Preoperative } \\
\text { Diagnosis }\end{array}$ & $\begin{array}{l}\text { Histological } \\
\text { Diagnosis }\end{array}$ \\
\hline & Symptomatic group & 90 Endometriomas & 90 Endometriomas & 1 Endometrioma & 1 Endometrioma \\
\hline & Asymptomatic group & 18 Endometriomas & 18 Endometriomas & 1 Endometrioma & 1 Endometrioma \\
\hline \multirow[b]{2}{*}{$\begin{array}{l}\text { False } \\
\text { positive }\end{array}$} & Symptomatic group & 2 Endometriomas & $\begin{array}{l}1 \text { Ovarian Torsion with Oophoritis } \\
1 \text { Hemorrhagic ovarian cyst }\end{array}$ & 3 Endometriomas & $\begin{array}{l}2 \text { Benign Serous } \\
\text { Cystadenoma } \\
1 \text { Serous Inclusion Cyst }\end{array}$ \\
\hline & Asymptomatic group & 20 Endometriomas & $\begin{array}{ll}8 & \text { Mature Cyst Teratoma } \\
4 & \text { Benign Mucinous Cystadenoma } \\
3 & \text { Benign Serous Cystadenoma } \\
3 & \text { Hemorrhagic ovarian cyst } \\
1 & \text { Borderline Serous Cystadenoma } \\
1 & \text { Fibroma with Minor Sex Cord } \\
\text { Element }\end{array}$ & 8 Endometriomas & $\begin{array}{l}6 \text { Mature Cyst } \\
\text { Teratoma } \\
1 \text { Carsinoid Tumor } \\
\text { Arising In a Mature } \\
\text { Cystic Teratoma } \\
1 \text { Serous Inclusion Cyst }\end{array}$ \\
\hline \multirow[b]{2}{*}{$\begin{array}{l}\text { False } \\
\text { negative }\end{array}$} & Symptomatic group & $\begin{array}{l}6 \text { Hemorrhagic cyst } \\
4 \text { Functional csyt } \\
1 \text { Teratoma }\end{array}$ & 11 Endometriomas & - & - \\
\hline & Asymptomatic group & $\begin{array}{l}5 \text { Hemorrhagic cyst } \\
2 \text { Teratoma } \\
4 \text { Unidentified } \\
2 \text { Malignant ovarian } \\
\text { mass }\end{array}$ & 13 Endometriomas & $\begin{array}{l}1 \text { Cyst with solid } \\
\text { component } \\
3 \text { Malignant ovar- } \\
\text { ian mass }\end{array}$ & 4 Endometriomas \\
\hline
\end{tabular}


Table III: Sensitivity, specificity, positive predictive value, negative predictive value, likelihood ratio( \pm ) and kappa values for preoperative diagnosis of endometriosis by history and routine clinical examination combined with transvaginal ultrasonography compared with histological outcome

\begin{tabular}{|c|c|c|c|c|c|c|c|c|}
\hline & $\begin{array}{l}\text { Sensitivity (\%) } \\
{[95 \% \mathrm{Cl}]}\end{array}$ & $\begin{array}{c}\text { Specificity (\%) } \\
{[95 \% \mathrm{Cl}]}\end{array}$ & $\begin{array}{l}\text { PPV (\%) } \\
{[95 \% \mathrm{Cl}]}\end{array}$ & $\begin{array}{l}\text { NPV (\%) } \\
{[95 \% \mathrm{Cl}]}\end{array}$ & $\begin{array}{c}\text { LHR+ } \\
{[95 \% \mathrm{Cl}]}\end{array}$ & $\begin{array}{c}\text { LHR- } \\
{[95 \% \mathrm{Cl}]}\end{array}$ & Kappa & $\begin{array}{c}p \\
\text { value }\end{array}$ \\
\hline $\begin{array}{l}\text { Total } \\
\text { population }\end{array}$ & $\begin{array}{l}79.7 \% \\
{[72,86]}\end{array}$ & $\begin{array}{c}91.2 \% \\
{[87.8,93.8]}\end{array}$ & $\begin{array}{c}76.9 \% \\
{[70.4,82.3]}\end{array}$ & $\begin{array}{c}92.4 \% \\
{[89.7,94.4]}\end{array}$ & $\begin{array}{c}9.03 \\
{[6.4,12.6]}\end{array}$ & $\begin{array}{c}0.22 \\
{[0.16,0.31]}\end{array}$ & $0.701[0.631,0.771]$ & $<0.001$ \\
\hline $\begin{array}{l}\text { Symptomatic } \\
\text { group }\end{array}$ & $\begin{array}{c}89.2 \% \\
{[81.5,94.4]}\end{array}$ & $\begin{array}{c}82.7 \% \\
{[64.2,94.1]}\end{array}$ & $\begin{array}{c}94.7 \% \\
{[89.1,97.5]}\end{array}$ & $\begin{array}{c}68.5 \% \\
{[54.9,79.6]}\end{array}$ & $\begin{array}{c}6.05 \\
{[4,10.4]}\end{array}$ & $\begin{array}{c}0.13 \\
{[0.07,0.23]}\end{array}$ & $0.670[0.810,0.530]$ & $<0.001$ \\
\hline $\begin{array}{l}\text { Asymptomatic } \\
\text { group }\end{array}$ & $\begin{array}{c}52.7 \% \\
{[35.4,69.5]}\end{array}$ & $\begin{array}{c}91.8 \% \\
{[88.4,94.5]}\end{array}$ & $\begin{array}{c}40.4 \% \\
{[29.7,52]}\end{array}$ & $\begin{array}{c}94.9 \% \\
{[92.9,96.3]}\end{array}$ & $\begin{array}{c}5.17 \\
{[2.3,11.5]}\end{array}$ & $\begin{array}{c}0.51 \\
{[0.36,0.73]}\end{array}$ & $0.393[0.536,0.250]$ & $<0.001$ \\
\hline $\begin{array}{l}\text { Premenopausal } \\
\text { period }\end{array}$ & $\begin{array}{c}81.8 \% \\
{[74.1,87.9]}\end{array}$ & $\begin{array}{c}91.7 \% \\
{[87.7,94.7]}\end{array}$ & $\begin{array}{c}83.0 \% \\
{[76.5,88]}\end{array}$ & $\begin{array}{c}91.1 \% \\
{[87.5,93.5]}\end{array}$ & $\begin{array}{c}9.86 \\
{[6.5,14.8]}\end{array}$ & $\begin{array}{c}0.20 \\
{[0.14,0.29]}\end{array}$ & $0.738[0.668,0.808]$ & $<0.001$ \\
\hline $\begin{array}{l}\text { Symptomatic } \\
\text { group }\end{array}$ & $\begin{array}{c}89.1 \% \\
{[81.3,91.4]}\end{array}$ & $\begin{array}{c}92.3 \% \\
{[74.8,99.5]}\end{array}$ & $\begin{array}{c}97.8 \% \\
{[92.2,99]}\end{array}$ & $\begin{array}{c}68.5 \% \\
{[55.2,79.4]}\end{array}$ & $\begin{array}{c}11.58 \\
{[3,43.9]}\end{array}$ & $\begin{array}{c}0.12 \\
{[0.07,0.21]}\end{array}$ & $0.721[0.582,0.860]$ & $<0.001$ \\
\hline $\begin{array}{l}\text { Asymptomatic } \\
\text { group }\end{array}$ & $\begin{array}{c}58 \% \\
{[39,75.4]}\end{array}$ & $\begin{array}{c}91.6 \% \\
{[87.3,94.8]}\end{array}$ & $\begin{array}{c}47.3 \% \\
{[34.9,60.1]}\end{array}$ & $\begin{array}{c}94.4 \% \\
{[91.7,96.2]}\end{array}$ & $\begin{array}{c}6.94 \\
{[4.1,11.6]}\end{array}$ & $\begin{array}{c}0.46 \\
{[0.3,0.69]}\end{array}$ & $0.453[0.297,0.609]$ & $<0.001$ \\
\hline $\begin{array}{l}\text { Postmenopausal } \\
\text { period }\end{array}$ & $33.3 \%$ & $89.1 \%$ & $15.3 \%$ & $96.0 \%$ & 3.30 & 0.74 & $0.150[-0.100,0.400]$ & 0.08 \\
\hline $\begin{array}{l}\text { Symptomatic } \\
\text { group }\end{array}$ & Tा & $\begin{array}{c}78.5 \% \\
{[49.2,95.3]}\end{array}$ & $\begin{array}{c}25.0 \% \\
{[10.8,47.6]}\end{array}$ & Tा & $\begin{array}{c}4.67 \\
{[1.7,12.7]}\end{array}$ & П & $0.328[-0.175,0.831$ & 0.08 \\
\hline $\begin{array}{l}\text { Asymptomatic } \\
\text { group }\end{array}$ & $\begin{array}{c}20 \% \\
{[0.5,71.6]}\end{array}$ & $\begin{array}{c}91.5 \% \\
{[84.0,96.2]}\end{array}$ & $\begin{array}{c}11.1 \% \\
{[1.8,44.9]}\end{array}$ & $\begin{array}{c}95.6 \% \\
{[93.2,97.1]}\end{array}$ & $\begin{array}{c}2.37 \\
{[0.36,15.4]}\end{array}$ & $\begin{array}{c}0.87 \\
{[0.56,1.36]}\end{array}$ & $0.084[-0.174,0.342]$ & 0.37 \\
\hline
\end{tabular}

PPV: Positive predictive value, NPV: Negative predictive value, LHR: Likelihood ratio. $5^{\text {th }}$ to $95^{\text {th }}$ percentile $[5,95 p]$ confidence interval $(95 \% \mathrm{Cl})$ values expressed within brackets. TThe values were not calculated because the number of patients was insufficient

Kappa analysis showed a good level of agreement in endometrioma diagnosis between TVS and histology in symptomatic premenopausal patients $(\kappa=0.72 ; 95 \% \mathrm{Cl}$ : $[0.582$ $0.860]$; $\mathrm{p}<0.001$ ) with a percentage of agreement of $89.7 \%$ (114/127), but this value for Kappa was a poor level of agreement in asymptomatic premenopausal patients $(\mathrm{\kappa}=0.45 ; 95 \%$ $\mathrm{Cl}:$ [0.297-0.609]; $\mathrm{p}<0.001)$ with a percentage of agreement of $87.7 \%$ (237/270). In symptomatic postmenopausal patients, Kappa analysis showed a fair level of agreement in patients with endometrioma $(\mathrm{K}=0.32 ; 95 \% \mathrm{Cl}$ : $[-0.175-0.831] ; \mathrm{p}=0.08)$ with a percentage of agreement of $80 \%(12 / 15)$; however, in the asymptomatic group, the value for Kappa indicated a poor level of agreement $(\mathrm{K}=0.08 ; 95 \% \mathrm{Cl}$ : $[-0.174-0.342] ; \mathrm{p}=0.37)$ with a percentage of agreement of $88 \%(100 / 115)$.

The most commonly encountered final pathology was a dermoid cyst in the patients who were preoperatively considered to have endometrioma. A dermoid cyst was detected in 8 of 22 premenopausal patients who were considered to have endometrioma and in 6 of 11 postmenopausal patients who were considered to have endometrioma. These cysts were encountered in the asymptomatic group of both premenopausal and postmenopausal patients. In the preoperative period, the most common false-negative diagnosis was a hemorrhagic cyst in patients who could not be diagnosed as having endometrioma (Figure 1). Of these patients, 6 were in the symptomatic group and 5 were in the asymptomatic group.

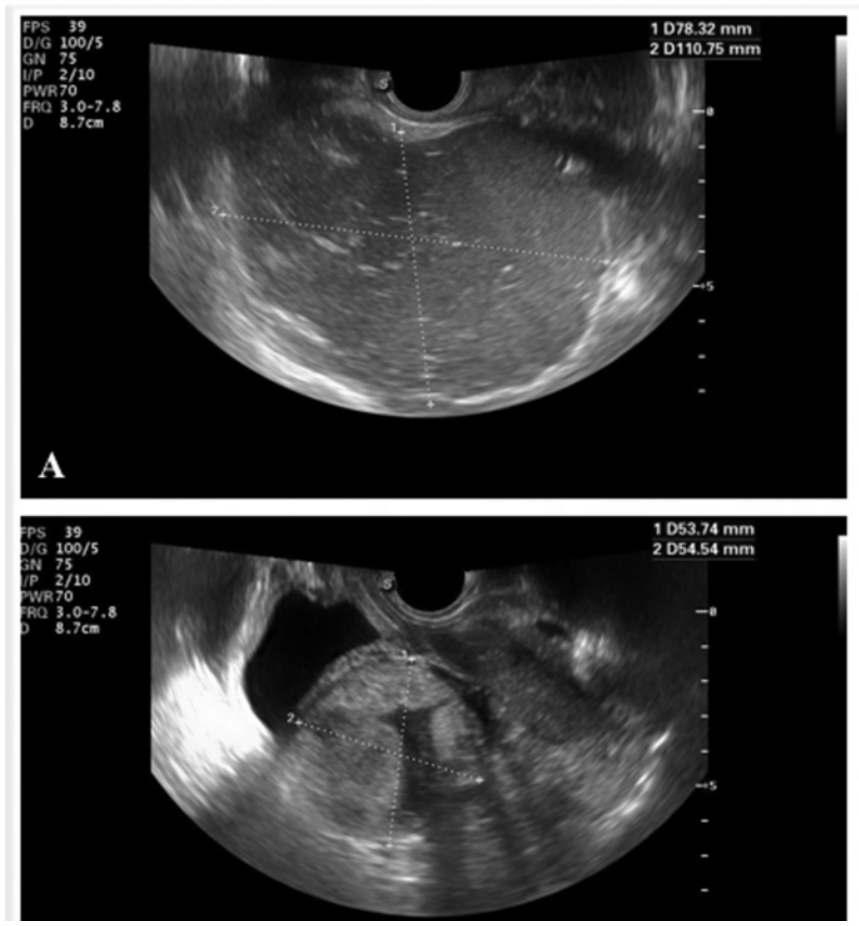

Figure1A: Dermoid cyst incorrectly classified as endometrioma (false positive); B: Endometrioma incorrectly classified as a dermoid cyst (false negative).

The histopathologic diagnosis was reported as malignant mass in a total of two patients (in the premenopausal and postmenopausal period) who were misdiagnosed as having endometrioma preoperatively. One of these patients was a pre- 
menopausal 42-year-old woman (gravida 2, para 1, abortion 1) who had a histopathologic diagnosis of fibroma with minor sex cord element. This patient had a mean cyst size of $6 \mathrm{~cm}$ and was admitted to the hospital for routine follow-up. The other patient was a postmenopausal 61-year-old woman (gravida 1, para 1) with a histopathologic diagnosis of carcinoid tumor arising in a mature cystic teratoma. The examination of this patient, who was admitted for a routine follow-up, revealed a 4-cm cystic mass. Both patients with malignancy who were falsely diagnosed as having endometrioma preoperatively were in the asymptomatic group.

\section{Discussion}

The results of the present study demonstrated that the TVS combined with the physical examination performed by a physician could predict endometrioma better in patients with signs and symptoms suggestive of endometriosis compared with asymptomatic patients at presentation.

Several studies made descriptions in an attempt to define the typical ultrasound characteristics of endometrioma. Sonographically, the most typical appearance of endometrioma includes a homogeneous, hypoechoic ovarian mass showing increased through transmission and containing homogeneous low or medium-level echoes in a ground-glass pattern (8). Additionally, the ancillary findings of endometrioma are punctate echogenic foci within the wall (B and D) and solid-appearing nodules due to clotted blood (A and C) (Figure 2) (4).
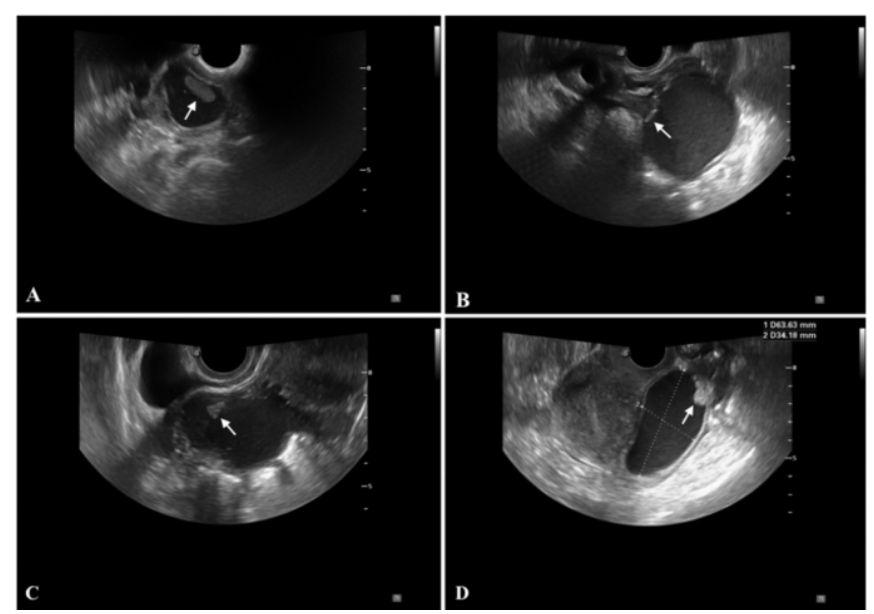

Figure 2: Punctate echogenic foci within the wall ( $B$ and $D$ ) and solid-appearing nodules due to clotted blood ( $A$ and $C$ ).

The presence of endometrioma can be considered as a marker for the diffuseness of pelvic endometriosis. The disease is present elsewhere in the pelvis or intestinal tract of almost $100 \%$ of patients with ovarian endometriosis. It rarely manifests with an isolated lesion. However, the main diagnostic problems of endometriosis include detecting and also determining the extent of the disease, especially in the absence of an endometriotic cyst. A recent international consensus em- phasized the need for a reliable diagnostic system of triage in order to evaluate the location and extent of deeply infiltrative endometriosis (DIE). In patients in whom endometrioma is considered, the physician should investigate the extent of the disease to check for severe and multifocal DIE lesions and enable referral to an appropriate surgeon with adequate experience in performing difficult laparoscopy (Figure 3). Patients with deep pelvic endometriosis may benefit from this strategy because every suboptimal attempt to excise endometriosis creates more fibrosis and adhesions, which makes further surgery more complicated $(9,10)$.
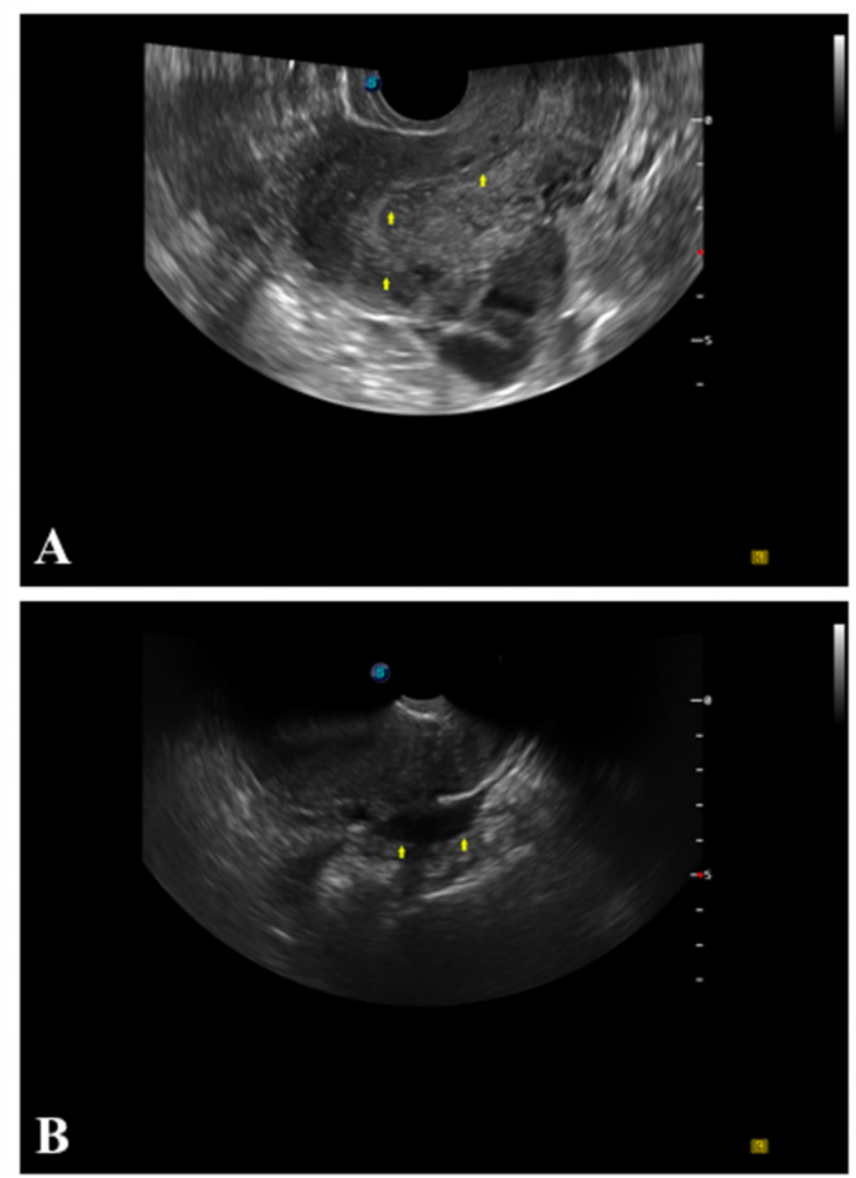

Figure 3: Adenomyotic uterus (A) (shown with the arrow; question mark) and rectal nodule (B) detected during the examination performed in the referral endometriosis unit of the patient who was diagnosed as having endometrioma during the first visit. A 34-year-old patient with deep infiltrating endometriosis underwent surgery due to her medical treatmentresistant

Among the patients whose final pathology was endometrioma, the rates of symptomatic and asymptomatic patients were $73.9 \%(102 / 138)$ and $26.1 \%(36 / 138)$, respectively. The association between endometrioma and painful symptoms has not been fully elucidated and remains controversial. In some cases, endometrioma, which is detectable by TVS, can be asymptomatic. Ovarian endometriomas can cause complications by forming adhesions that can fixate pelvic organs and alter the normal course of tubes or occlude them. The fixation of pelvic organs may distort anatomic sites, thereby causing 
painful symptoms (10). According to Fauconnier et al., ovarian endometriomas do not contribute to chronic pelvic pain but are highly associated with DIE, which is known to cause chronic pelvic pain (12). Women with peritoneal endometriosis have an increased volume of peritoneal fluid including elevated levels of macrophages and various proinflammatory cytokines, which can be the cause of painful symptoms. Opoien et al. found no direct relationship between ovarian endometrioma and the proinflammatory process, similar to that in the case of peritoneal endometriosis (13). Currently, little is known about the pain-causing mechanisms that may be associated with endometrioma. Therefore, while creating a treatment plan for women with chronic pelvic pain and endometriomas, the physician may also need to consider treating the deep infiltrates (14).

Hudelist et al. assessed the combined diagnostic performance of TVS and clinical examination performed by two expert physicians in patients with pelvic pain and suspicion of endometriosis and determined the sensitivity to be $96-100 \%$ and specificity to be $99-100 \%$ (15). Another study by Guerriero et al. revealed the sensitivity and specificity of clinical examinations combined with TVS performed preoperatively for endometrioma as $90 \%$ and $95 \%$, respectively, in patients who underwent surgery for suspicious rectovaginal endometriosis (16). In both studies, the results of referred patients with suspected endometriosis who were examined by an expert surgeon were reported. In a study by another researcher, these ratios were $90.4 \%$ for sensitivity and $91.5 \%$ for specificity (17). In that study, the researchers were blinded to the physical examination and other imaging modalities of the patients although they were aware of their symptoms and histories. In our study, the sensitivity and specificity for symptomatic patients were found as $89.1 \%$ and $92.3 \%$, respectively. In contrast, the sensitivity and specificity in asymptomatic patients decreased to $58 \%$ and $92.3 \%$, respectively. The probable reason for these rates to be lower in our study compared with the above-mentioned studies may be the inclusion of more than one physician with different clinical experience and that the examined population was composed of self-referred patients who were admitted to the hospital with various symptoms not limited to endometriosis. These different statistical results expressed for the preoperative diagnosis of ovarian endometrioma may originate from the difference in the study design. The symptoms presented by the patients during the examination seemed to encourage the physician to diagnose endometriosis more frequently.

The subjective impression can cause malignancies to be misclassified as endometriomas in $0.2-0.9 \%$ of cases (4). In our study, due to the subjective impression, one of the 130 $(0.76 \%)$ premenopausal patients and one of the $13(7.6 \%)$ postmenopausal patients who were suspected of having endometrioma had a malignant tumor. This rate was 19\% in postmenopausal patients in another series (8). The reason for this ratio to be higher in postmenopausal patients compared with premenopausal patients can be explained by the different appearance of endometriomas in ultrasonography. The endometriomas of postmenopausal patients manifest with unilocular cysts and ground-glass echogenicity less frequently. In fact, the ability to recognize an endometrioma in postmenopausal patients is clinically much less important compared with premenopausal patients. The main goal of physicians in the postmenopausal group is to focus on identifying malignant masses. The patients with malignancy who had an incorrect diagnosis of endometrioma in our series were in the asymptomatic group.

There are several principal limitations to our study. First, because this was a retrospective study, the assessment of the patient's history and symptoms were not standardized, which requires a questionnaire. This might lead to variable recall concerning the description of the symptoms. However, it is unlikely that this variable caused bias because the history, physical examination, and TVS were performed by the same physician. Another limitation is that, despite the high number of premenopausal patients, the number of postmenopausal patients was too low for a precise estimation of statistical results. The physicians performing the examination considered that some patients had DIE in different anatomic locations in which endometrioma did not accompany. The patients included in our study were limited to only ovarian masses. Moreover, because DIE was beyond the scope of our study, it was not analyzed in our article as a separate parameter. These patients were referred to the endometriosis unit of our hospital for further investigation. The most powerful aspect of our study is that it is a single-center study including many gynecologists with various levels of experience and a general population in the outpatient clinic. This makes our results more likely to be generalized compared with studies that include a single expert examiner and referral of patients who are suspected of endometriosis to an endometriosis center.

To the best of our knowledge, the present study holds the distinction of being the first to evaluate the diagnostic performance of TVS combined with physical examination in predicting endometrioma preoperatively in patients with asymptomatic presentations and symptomatic patients. It is important to be aware that the apparent results of subjective assessment regarding the specific diagnosis are influenced by the ultrasound examiner's skill and endometriosis experience, and by the quality of ultrasound equipment used.

\section{Conclusion}

The diagnostic performance of TVS in combination with the physical examination in patients with asymptomatic endometrioma cannot reach the diagnostic accuracy of physical examination combined with TVS performed in patients with endometrioma who present symptomatically. 
Acknowledgments: We would like to thank David F. Chapman, $B S c$, for editing the article.

The authors do not have any conflict of interest or financial support.

This study was conducted in accordance with the Declaration of Helsinki and obtained the consent for using data.

Author contribution:TT: Idea, concept, writing the article, resources, funding, materials. TK:Design, source scan, writing the article. SY: Data collecting, processing. EO: Analysis,comment, critical review. HK:Data collecting, processing. EO:Check, consultancy.

\section{References}

1. Yeung PP Jr, Shwayder J, Pasic RP. Laparoscopic management of endometriosis: comprehensive review of best evidence. J Minim Invasive Gynecol. 2009;16(3):269-81.

2. Ballard K, Lane H, Hudelist G, Banerjee S, Wright J. Can specific pain symptoms help in the diagnosis of endometriosis? A cohort study of women with chronic pelvic pain. Fertil Steril. 2010;94(1):20-7.

3. Kawaguchi R, Tsuji Y, Haruta S, Kanayama S, Sakata M, Yamada Y, et al. Clinicopathologic features of ovarian cancer in patients with ovarian endometrioma. J Obstet Gynaecol Res. 2008;34(5):872-7.

4. Exacoustos C, Manganaro L, Zupi E. Imaging for the evaluation of endometriosis and adenomyosis. Best Pract Res Clin Obstet Gynaecol. 2014;28(5):655-81.

5. Utian WH. The International Menopause Society menopause-related terminology definitions. Climacteric. 1999;2(4):284-6.

6. Timmerman D, Ameye L, Fischerova D, Epstein E, Melis GB, Guerriero S, et al. Simple ultrasound rules to distinguish between benign and malignant adnexal masses before surgery: prospective validation by IOTA group. BMJ. 2010;14:341.

7. Landis JR, Koch GG. The measurement of observer agreement for categorical data. Biometrics. 1977;33(1):
$159-74$.

8. Chapron C, Pietin-Vialle C, Borghese B, Davy C, Foulot $\mathrm{H}$, Chopin H. Associated ovarian endometrioma is a marker for greater severity of deeply infiltrating endometriosis. Fertil Steril. 2009;92(2):453-7.

9. Chapron C, Santulli P, de Ziegler D, Noel JC, Anaf V, Streuli I, et al. Ovarian endometrioma:severe pelvic pain is associated with deeply infiltrating endometriosis. Hum Reprod. 2012;27(3):702-11.

10. Hirsch M, Begum MR, Paniz E, Barker C, Davis CJ, Duffy J. Diagnosis and management of endometriosis: a systematic review of international and national guidelines. BJOG. 2018;125(5):556-64.

11. Fauconnier A, Chapron C, Dubuisson JB, Vieira M, Dousset B, Breart G.Relation between pain symptoms and the anatomic location of deep infiltrating endometriosis. Fertil Steril. 2002;78(4):719-26.

12. Opoien HK, Fedorcsak P, Polec A, Stensen MH, Abyholm T, Tanbo T. Do endometriomas induce an inflammatory reaction in nearby follicles? Hum Reprod. 2013;28(7): 1837-45.

13. Keyhan S, Hughes C, Price T, Muasher S. An update on surgical versus expectant management of ovarian endometriomas in infertile women. Biomed Res Int. 2015;2015:204792.

14. Hudelist G, Oberwinkler KH, Singer CF, Tuttlies F, Rauter $\mathrm{G}$, Ritter O, et al. Combination of transvaginal sonography and clinical examination for preoperative diagnosis of pelvic endometriosis. Hum Reprod. 2009;24(5):1018-24.

15. Guerriero S, Ajossa S, Gerada M, D'Aquila M, Piras B, Melis GB. "Tenderness-guided" transvaginal ultrasonography: a new method for the detection of deep endometriosis in patients with chronic pelvic pain. Fertil Steril.2007;88(5):1293-7.

16. Bazot M, Thomassin I, Hourani R, Cortez A, Darai E. Diagnostic accuracy of transvaginal sonography for deep pelvic endometriosis. Ultrasound Obstet Gynecol. 2004; 24(2):180-5. 